\title{
Viendo Pasar Nuestro Cine: algunas consideraciones
}

\author{
José Guadalupe Figueroa Soria \\ Facultad de Ciencias Políticas y Administración Pública UAEM
}

\section{Introducción}

El 14 de agosto de 1996 se cumplieron 100 años de la presencia del cine en México. Un día como tal, en el sótano de la calle de Plateros -hoy Madero- fueron exhibidas públicamente algunas vistas realizadas por los hermanos Lumiére. (De la Torre. 1996: 7) Entonces, es así como se cumplen cien años de la llegada del cine a México, ese mismo año de 1996 se cumplieron también cien años de ver10 pasar de una industria de la cultura a una industria de productos mercantiles, destinados al úselo y tíre 10 característicos de una sociedad que tiende al entretenimiento desechable, como uno más de los síntomas de nuestra cultura posmoderna actual, donde la cotidianidad se construye a base de inmediateces super o sobrepuestas unas con otras; claro está, sin dejar de reconocer con lo dicho, que este arte haya sido también uno de los pilares históricos fundamentales en la formación de estereotipos Y clichés de eso que llamamos "la mexicanidad", en un cine que ha pretendido ir a la conciencia popular, y que por ello, por haberlo logrado plenamente, lo hace objeto de reflexiones orientadas a entenderlo y comprenderlo en sus diferentes vertientes y miradas que lo envuelven.

Estos apuntes ${ }^{1}$ tienen, como fin último, el de llamar la atención sobre aquello que ahora nos convoca, el llevar al análisis un problema que ha trascendido el puro ámbito de lo cinematográfico, para instalarse cómodamente también en los espacios propios de la comunicación. Espacios que lo recuperan sin analizar muchas veces las prerrogativas o las limitantes que conlleva la investigación particular en cine, pero que lo abordan tratando de dar cuenta de esas prácticas de comunicación que a partir de él se generan; y todo esto sin el afán de quererse involucrar en los espacios íntimos de la realización cinematográfica, ya que para ello existen sus espacios propios de formación profesio-

1 Ponencia presentada en el Primer Encuentro Nacional sobre la Enseñanza y la Investigación del Cine en México, realizado en la Universidad Autónoma Metropolitana (UAM-X) de la Ciudad de México, del 26 al 28 de septiembre de 1996 Versión ampliada y corregida 
nal de cineastas, espacios donde los que miramos desde la comunicación poco podemos aventurar a proponer, sino es que simplemente como una línea de investigación a desarrollar, una línea por cierto que cuenta con expectativas muy amplias de desarrollo para dar cuenta también del devenir social.

¿Para qué investigar el fenómeno cine desde la comunicación?, ¿cómo realizar dicha investigación?, ¿dónde aterrizarla?, y ¿a qué beneficios nos lleva esta interdisciplinariedad de enfoques?; son cuestionamientos a los que urge dar respuesta en estos tiempos de crisis cinematográfica agudizada, por lo que, más que dejarlos resueltos, este cúmulo de apuntes mínimos sugiere abordarlos y generar nuevas dudas, e incluso ampliar la ya existentes, con lo cual se nos permitirá plantear un panorama más claro y alentador de la compleja, y a veces ambigua, problemática que se nos presenta.

Y es que dentro del ámbito de lo comunicativo, una vertiente que se erige como campo de estudio, es lo cinematográfico, el que puede instalarse como una línea investigativa en las escuelas de comunicación, con el fin de que poco a poco nos permita construir, por ejemplo, mapas de consumo cultural en nuestro entorno próximo, que nos dé la posibilidad de comprender los procesos de recepción en los espectadores, y que nos facilite la explicación en cuanto a la creación de sistemas simbólicos por parte de esos públicos y de las diversas maneras de recrear la realidad a partir de lo visto en la pantalla, sin dejar de lado los aspectos determinantes de producción y circulación, tanto a nivel nacional como en la entidad, o en las diversas y múltiples entidades que conforman la realidad nacional, porque no sólo se trata de dar cuenta de lo estatal como ente geográfico y/o político y cultural, sino de los mapas sociales y simbólicos de las poblaciones, y de sus intrincadas redes de interactuación, redes que son patentes en la intertextualidad de los discursos o en la resemantización de los mensajes por parte del cinéfilo, resemantización que se asume con significaciones diversas..

Así, el presente ensayo se estructura en tres apartados básicos que tratan de dar cuenta y, en algún caso, dejar establecidas las pistas con las que sea posible dar respuesta a la problemática planteada. En el primero, se aborda el contexto histórico-social de la evolución que ha tenido el cine a lo largo de estos cien años; en el segundo, se propone un acercamiento a la manera de cómo explicar desde lo académico la cuestión cine, haciendo énfasis en los marcos teóricos y metodológicos que tratan de explicar el objeto de estudio; y por último, si a partir de todo esto, se llega a conclusiones que más que ser fines últimos en sí mismos, son simples parámetros que pretenden determinar las dimensiones del fenómeno cine como línea de investigación desde lo comunicativo. Pasos necesarios para englobar una perspectiva más cercana a una explicación puntual de todo lo que envuelve este fenómeno. 


\section{La Problemática cinematográfica. Más allá del cine}

Se dice que el cine involucra al hombre común... (que) se ha transformado en una fuente de información de todo tipo y (que) ha influido en las conductas, los modos de vida, las pautas sociales y morales. Por tal motivo debe interesamos, porque es un factor de cambio o de estancamiento social, según sean las intencionalidades puestas en juego en su elaboración. (Poloniato, 1992:9).

Eso y más es el cine, es un mundo de significaciones que ya ha trascendido de ser un mero entretenimiento para constituirse en una parte muy importante de nuestra cultura (Poloniato, 1992). Y es que desde su surgimiento mismo, ha tenido en su esencia el germen de llegar a las conciencias, de instaurarse como esa máquina de sueños realizables para el hombre a través de las imágenes, de las historias y de los contenidos; del entrelazamiento de las figuras de una realidad inalcanzable pero realizable, con las figuras a las cuales se aspira a ser y aparecer, de las figuras de una representación social de la realidad, de un recorte de historias propias y ajenas que ahí toman vida, pero que también salen de las pantallas y se insertan en la vida cotidiana para determinar modos y estilos de comportamiento, de conocimiento, de idolatría, en fin, de las aspiraciones soñadas e intentadas (pero fracasadas) de todos nosotros. Esto y más es el cine, el medio de comunicación que se conforma como el más completo, y por ello su estatuto de ser considerado como el séptimo arte. Y por ello mismo también, una actividad que involucra múltiples problemas, variadas formas de verlo, de sentirlo, de apropiarlo, de significarlo en direcciones y sentidos que parecen no tener fin, de crearse un concepto y un ritual para percibir los mensajes que de él emanan. Así es el cine, y por eso en este apartado se pretende poner en la mesa de las discusiones algo de lo mucho que salta a la vista.

El cine y su producción han evolucionado de una manera bastante acelerada; un breve repaso a los momentos por los que ha pasado en las hojas de cualquier enciclopedia o recuento histórico, así lo demuestran (como son los casos de la serie "Los papeles de cine ", la "Historia documental del cine mexicano ", o el ya clásico " $A B C$ " del maestro Ayala Blanco, por citar algunos ejemplos bien conocidos); pero no podemos decir lo mismo acerca de los momentos por los que ha pasado el estudio de esta actividad, de este arte, y de la función social que juega.

Si bien existen obras fundamentales, bibliografía suficiente, como para dar cuenta de lo que el cine es, cómo se produce y cómo circula, aspectos muy importantes también para comprenderlo totalmente, aún nos sigue faltando información que nos diga qué función ha tenido en la construcción de 
imaginarios colectivos, en la tan discutida manipulación de la realidad o en la generación de un sentido como producto que incide directamente en la conciencia del espectador, en la parte que le corresponde de ese imaginario social al que pertenece.

Imaginarios colectivos que aquí se entenderán como aquellos procesos que "evocan en su acepción corriente la producción de ilusiones, simbolos, quimeras, evasiones siempre de la dura realidad de los hechos. El mundo imaginario... queda reservado al mundo de la literatura, de la poesía o de las artes" (Colombo, 1993:7).

Esta cuestión del sentido y su análisis, es la que más se nos aparece como fundamental para abordar, con una mirada crítica, a la realidad cinematográfica; queriéndose decir con esto, la investigación sobre y acerca del cine, ya no digamos de la pura formación de profesionales, léase cineastas, ni mucho menos de la de los críticos de cine. Porque no basta con encontrar buenas peliculas o promover que las producciones y exhibiciones tiendan a mostrar dichos buenos productos, sino que es indispensable y urgente conocer los impactos, los efectos o, sencillamente, los modos de recibir las cintas y sus historias, saber qué pasa con aquél que consume el cine, y más particularmente nuestro cine, labor que desde lo comunicativo puede ser abordada con resultados adecuados para explicar la cuestión social del espectador.

$Y$ es que al fin de cuentas, se coincide con Néstor García Canclini cuando dice que el espectador de cine fue un invento del siglo XX, de la modernidad, ya que "se aprendió a ser espectador de cine, ir periódicamente a las salas oscuras, elegir la distancia adecuada de la pantalla, disfrutar de las películas solo o acompañado, pasar de la intimidad de la proyección al intercambio de impresiones y la celebración gregaria de los divos" (García, 1994: 15), de generar expectativas de vida y de sueños, de imaginarios y de verosímiles, de lo visto y hablado en la película.

Así, ya desde las investigaciones realizadas en la década de los años setenta, se ponía énfasis en el aspecto de las enormes ganancias que la exhibición y distribución de las películas generaba, y que sobrepasaba a otras formas de espectáculo, como el teatro y los deportes por sólo nombrar dos, en el orden de cinco veces más (Gomezjara, 1973:47). Y asimismo, me parece que habría que rastrear esta situación desde los inicios primeros de la cinematografía nacional, porque es desde allí mismo, desde el año de 1921, cuando "la producción de cine mexicano languidece. El cine norteamericano produce de 500 a 700 películas anuales, desplazando al europeo y llevando al cine mexicano a una competencia insostenible" (González, 1996:8). 
De la misma manera, se nos mostraba que la relación entre lo nacional y lo importado, en cuanto a origen de las películas exhibidas se refiere, se contaba alrededor del 35\% y del 65\%, respectivamente (Gomezjara, 1973:53). Prácticas que no han cambiado mucho a lo largo de estos dos últimos decenios, tal como lo deja ver el sondeo que sobre consumo cultural de los medios en el Distrito Federal hiciera el diario Reforma en ese año de 1996, y que retornó la Revista Mexicana de Comunicación, donde se muestra claramente que la población sigue prefiriendo lo producido por el "star system" norteamericano (Alva, 1996:38); es más, se puede decir que la brecha se ha agrandado conforme la tendencia es expander el número de las salas cinematográficas para dar cabida a más públicos, como es el caso de la alianza que recientemente formaran la compañía "Cinema United Artist" con la empresa "Fondo Optima” S.A. de C. V:, alianza con que pretenden establecer 25 complejos cinematográficos (aproximadamente 250 pantallas), en un plazo de no más de cinco años, obviamente en lugares estratégicos de población en cuanto a importancia económica se refiere, como lo son Guadalajara, Aguascalientes, León y el Distrito Federal, aparte de las multisalas ya existentes en las grandes urbes, en donde de quince de ellas una o dos se destinan solamente a exhibir cine "made-in" México.

Pero ahí no para la cosa; por otro lado, y ante las recesiones económicas constantes, el aficionado al cine va cada vez menos, y sólo a ver películas que le provocan, o bien el éxtasis de la autoestima heroica, o bien el refugio que lo ponga a salvo de una realidad tan cruel o más que la vista por esa fábrica de ensueños que lo frustra sistemáticamente; y esto es algo parecido a lo que habla Carlos Monsiváis, al decir que ante tanta desesperanza, al mexicano le queda sólo el camino de crear rituales de autoestima personal en momentos claves del día para sortear toda esta serie de contratiempos, donde quizá sea uno de ello el ir al cine, en la sala si lo permite el bolsillo, o en casa por medio de la piratería de los estrenos. En el mismo estudio realizado por Reforma, se observa que el $70 \%$ de los encuestados cuenta con video casetera, y que de ellos el $64 \%$ renta películas con fines de entretenimiento (Alva, 1996:38).

Entretenimiento que se refleja en películas de acción y de suspenso principalmente; y para demostrar esto basta con echar una mirada a las carteleras del día, para saber que en su mayoría se exhiben thrillers o suspenses que tienen la finalidad última de evadir de la realidad al espectador, amén de ser cintas encaminadas o consideradas como entretenimiento. Otra más, ese cinéfilo en potencia tiende a esta otra opción de consumo, a la oferta del videohome, para evitarse la pena de ser robado o de pasar un mal rato con las malas 
exhibiciones que se hacen en ciertas salas de barrio, tanto en audio como en imagen, lo que implica ser un tipo más de robo concertado. Pero en ello hay implicaciones dignas de observar; por un lado, aumenta la renta semanal de películas en vídeo, reflejo quizá del creciente factor de desempleo y que por lo tanto se convierte en un mecanismo para cubrir el tiempo libre, y una tendencia mayor hacia el aislamiento social (producto también del incremento en la tasa de violencia callejera); por el otro, el uso de la nueva tecnología con objetivos mínimos de utilización, ya que no se conocen o vislumbran las posibilidades de uso que tiene esa tecnología con la que se cuenta en casa, lo que implica además una falta de creatividad intelectual ante la utilización de los recursos tecnológicos, traduciéndose esto en un problema de receptividad pasiva de los mensajes por parte del consumidor de los medios.

¿Y esto a qué se debe? Son muchas las cuestiones a considerar. Una de ellas tienen que ver con el concepto mismo del ver cine. Para responder tenemos que considerar el hecho inevitable de que desde el acto mismo de la invención y de la realización del film como «narración», venía actuando, casi sin consentimiento del público, aquel medio expresivo que había ya menoscabado, minado, gran parte de la razón de ser del teatro, de la ópera lírica y de otro género de espectáculo (Dorfles, 1993:67). Medio que transferido después a la pantalla de televisión, debía de hecho mezclar lo "verdadero" con lo "inventado ", lo documental y lo ficticio, la "tranche de vie" y el suceso periodístico, hasta el punto de hacer posible la consideración definida y objetiva de un elemento existencialmente activo o de uno estéticamente nulo a través de una auténtica "carga afectiva" y de una análoga indiferencia estética (Dorfles, 1993:225).

No hay corresponsabilidad entre una cosa y la otra, o aparentemente no debiera haberla; puesto que la cuestión artística del cine ahora ya no conlleva discusiones como las que se generaron en otras épocas sobre su carácter artístico, sino que más bien la discusión actual gira en tomo a lo que se expresa en la pantalla, al manejo de ciertos temas, o al fin con que se ruedan las cintas. Ejemplifico: si vemos a los hermanos Almada tirar bala contra narcos y seudo policías o funcionarios públicos corruptos, pensamos que es un cine de mala calidad; ciertamente no las podríamos considerar dignas de obtener premios en "Cannes" o aspirar a que se gane, con dichos productos, todos los "Oscares" holiwoodenses en el renglón del premio a la mejor película extranjera, y tal vez ni siquiera ser consideradas como aspirantes a obtener los premios "Arieles" mexicanos, pero no pensamos tampoco en la manera en que son apropiadas por los grandes públicos que las consumen, por la manera en que se ponen de manifiesto y se movilizan los imaginarios colectivos de la "raza", 
que ve ahí reflejados, recreados, re-presentados, unos cortos de sus anhelos y de sus pasiones más ocultas. $\mathrm{O}$ si no preguntémonos, y preguntémosle, cuál es la finalidad de Carlos Monsiváis al caracterizar a un jefe, de algún Cártel de la droga, en cierta cinta ("La guerrera vengadora III"), si esa no tuviera nada que ver con la realidad inmediata que promueve prácticas y procesos de comunicación específicos en los segmentos de población que las consumen.

He aquí el eje central con el cual debemos establecer un diálogo permanente al realizar investigación sobre cine desde el ámbito de la comunicación, de lo comunicativo. Y es que esas prácticas nos dan la pauta para comprender mejor el papel social del cine, el rol que juega dentro de cada estrato social, el simbolismo que se extrae de él para incorporarlo a la cotidianidad personal y colectiva. Todo esto tiene que ver con la clasificación o estratificación de los públicos, de los consumidores, es decir, para ponerlo en términos cinematográficos, de los espectadores. Y es que solamente con la comprensión plena de estos segmentos de población, es como podemos encontrar los tipos de consumo, los mapas que sean indicadores del modo de significar los mensajes, en fin, de la construcción de simbolismos en el imaginario social que a cada momento se recrean en las instituciones sociales donde se desarrolla e interactúa el espectador, el receptor de los mensajes cinematográficos.

Y prueba de ello, de que el cine va más allá de la simple pantalla, resulta ser el hecho, quizá único por ser México, y producto también del surrealismo con el que nos expresamos a diario en este país de surrealismos encontrados, de que durante el "Congreso Para el Fortalecimiento de la Cinematografia", llevado a cabo hace poco en la ciudad de México ( $1^{\circ}$ semestre de 1996), el presidente del CEN del PRI diga que debemos “... hacer del cine un medio de promover la bandera del PRI ..." (palabras textuales hechas públicas por el noticiero "Hechos" del canal 13 de TV-Azteca, transmitido el 30 de mayo de 1996).

Declaración por demás comprensible si la tomamos así, de quien viene, porque en la realidad vemos que el cine mexicano de 1995 se caracterizó por la tendencia a borrar drásticamente los muchos valores que sustentaron sus vicios (García, 1996: 20), sus servicios, su negación del vacío que ahora parece tener como derrotero que le ubica en los cambios posmodernos, situación plenamente contradictoria de la que aquí el político pretende crearle. Pero ello también nos indica que el poder de la pantalla grande puede seguir teniendo, que lo tiene, un poder de manipulación o de toma de conciencia social bastante amplia, según como se le considere y se le use.

Retornando lo que tiene que ver con la producción cinematográfica de los últimos tiempos en México, se coincide con Gustavo García cuando dice 
que ésta ya quedó en el basurero social, que la estrecha relación que se tenía con el público y el interés productivo de las iniciativas privadas y públicas, ya también pasó a la historia. Y nos remite a ver cómo las películas mexicanas poco a poco han ido desapareciendo de los gustos del espectador y del interés de los productores, dándonos datos que se convierten en alarmantes y desalentadores para los buenos creadores nacionales; ejemplo de ello, es que de un tercer lugar en taquilla en 1992 para una "buena" cinta nacional ("Se equivocó la cigüeña" de María Elena Velasco "La india María"), se ha pasado a un noveno lugar en 1995 para una cinta de un conacional ("Un paseo por la nubes” de Alfonso Arau), es decir, que si no es por Alfonso Arau tal vez estaríamos hablando ya de una desaparición total de' lo hecho en México, sin olvidar que ésta última no fue producida aquí, en fin, triste consuelo (García, 1996:20-21).

Si bien esta situación es un reconocimiento al talento de los directores mexicanos, como lo es el de Arau, también es cierto que la fuga de cerebros cinematográficos se está convirtiendo en el bracerismo del cine ante la grave situación por la que atraviesa la industria nacional actualmente. Desde hace años hemos visto cómo muchos directores y productores han optado por filmar en los Estados Unidos, donde los costos de producción se reducen considerablemente y donde las historias que ahí se presentan son pensadas con fines exclusivamente comerciales y garantizan una recuperación económica rápida al ser exhibidas en México; y que conste que no se está en contra del factor comercial, puesto que al ser productos de una industria, necesariamente se busca un beneficio con su circulación y consumo, pero ello no es indicativo de que se tenga que sacrificar la calidad por la cantidad. Y cuando la ganancia de exhibición comienza a decaer en las salas de cine, entonces se recurre a la distribución del cine más comercial de Norteamérica, ese que se distribuye mundialmente y que también garantiza la ganancia económica rápidamente.

Ante el panorama descrito, ante la inminente puesta en circulación de cintas importadas desde los Estados Unidos, puesto que las producciones europeas y asiáticas, o en su defecto las latinoamericanas, brillan por su ausencia, o sencillamente van encaminadas a públicos minoritarios, vuelve a surgir el tema del punto que se ha convertido en el gran ausente de las investigaciones sobre y acerca del cine, el hecho de saber qué pasa con aquél que recibe estos mensajes, cómo los negocia en su cotidianidad, qué efectos o impactos se están generando a partir de esa masificación de los contenidos del "american way a lile ", de esos estilos que además tienen un fin de probable ideologización al transmitir esa forma de vida como la única, real y verdadera, la occidentalización de las miradas. 


\section{Hacia una resolución de la mirada cinematográfica desde la comuni- cación. Retos y perspectivas}

Que el cine sea un medio de comunicación basado en códigos, no significa que permanezca inmutable, rigidamente en géneros y en forma expresiva. Las lenguas naturales y el lenguaje cinematográfico son creativos. Hay una creatividad que se expresa 'dentro de las reglas' (haciendo uso de la libertad combinatoria) y otra 'fuera de las reglas' (inventando nuevas relaciones). Este hecho es claro en poesía y debe serio en el cine. (Poloniato, 1992:57).

Esta multiplicidad de formas y de discursos, son los que identifican al cine como un medio de comunicación y como un arte, como una forma de expresión particular que genera códigos identificables por el espectador, códigos que son o no retornados para su manera de conducirse en su cotidianidad

Para abordar el cine con esta perspectiva, es necesario ubicamos en dos puntos de partida, dos tendencias que desde lo teórico y lo metodológico podrán dar cuenta de los procesos y las prácticas de comunicación generadas por la pantalla grande. Puntos de vista que tienen que ver además con lo visual y con los imaginarios colectivos, con los verosímiles de la realidad producidos en y por los públicos a partir de su interacción en diversos ámbitos institucionales donde actúa e interactúa.

Una de ellas, de esas perspectivas, es lo que conocemos como el análisis de contenido, vertiente que se nutre con lo semiótico y que pretende desentrañar el contenido implícito en los productos sociales. La otra, va encaminada al trabajo con el espectador, con el consumidor de los mensajes cinematográficos. y que se nutre de las tendencias críticas de los medios, surgidas en Latinoamérica y que, a últimas fechas, ha desembocado en una perspectiva que trata de dar cuenta de las diversas lecturas de un mensaje, de su resemantización social, y de la puesta en juego dentro de la cotidianidad. En conjunto, ambas quieren proponer modos de averiguar qué hacemos con lo visto en los medios, qué hacemos con lo cinematográfico, para el caso particular que nos ocupa.

En cuanto a la primera, el análisis de contenido, nos remite necesariamente al hecho de conocer los modelos metodológicos que facilitan la decodificación del film en sus diversos componentes: la imagen, la música y la narración. Con ellos es posible contar con los significados del contenido y los intereses del realizador. Aspecto que conlleva a otro problema paralelo a éste, y que tiene que ver con la enseñanza del cine en comunicación, y es que en la medida en que no podamos ser realizadores, y creo que tampoco está en nuestras perspectivas serlo, en esa misma medida debemos incursionar en el conocimiento de trabajos ya realizados, que a su vez nos permitan saber los modos de concebir la realidad de una época determinada, de un autor, o de 
un tipo y género de hacer cine(s). Para ello basta con nombrar dos marcos teóricos y metodológicos que se han establecido como eficaces para alcanzar y explicar dicho objetivo, me refiero al de Gianfranco Bettetini y al de Jacques Aumont, quienes desde las escuelas italianas y francesas, respectivamente, han procurado sistematizar la estructura del film con fines de análisis.

Por su parte, Bettetini pone énfasis en la "lectura" del tiempo y su representación, así como en la articulación temporal en que se organiza el material significante, énfasis que conlleva a esclarecer los problemas de la enunciación; proceso que dentro del material significante realiza allí un conjunto de actos de significación, es decir, de diégesis, semióticamente hablando. Mientras que Aumont, por su lado, enfoca el análisis del discurso cinematográfico en tanto films, considerados como obras en sí mismas, independientes e infinitamente singulares; se trata, en última instancia, de concebir el análisis del film como una obra artística autónoma, capaz de engendrar un texto (análisis textual) que fundamenta sus significaciones sobre estructuras narrativas (análisis narratológico) y sobre bases visuales y sonoras (análisis icónico), produciendo así un efecto particular sobre el espectador (análisis psicoanalítico).

Ambos modelos tienen, como finalidad general, la de decodificar los contenidos de las películas, tradición que ha tenido que ver con una necesidad académica que se desarrolla por la década de los años 70's en casi todas las áreas de las ciencias sociales, y que conlleva aparejada otra necesidad, la de explicar la ideología implícita en las cintas, además de proponer un disfrute supuestamente más completo de los films por parte del espectador.

La utilización de ambos marcos de análisis no debe dejar de lado que la finalidad última es encontrar un sentido social del trabajo cinematográfico, porque tampoco nos serviría de mucho conocer únicamente la cuestión estructural. Sino que es necesario ir más allá de la simple puesta en práctica de modelos explicativos, para obtener modelos interpretativos y explicativos que podamos usar con fines todavía más precisos en la comprensión de lo social.

Dentro de esta perspectiva, habría que mencionar necesariamente los aportes que desde México ha venido realizando al análisis estructural del film Lauro Zavala $(1993,1994,1995,1996)$, quien incursiona en la cuestión de la intertextualidad de los discursos como síntoma inequívoco de la producción cotidiana de la modernidad. Son aportes que se han venido construyendo, si bien a partir de marcos teóricos universales, sin olvidar tampoco el contexto particular de donde parten, es decir, desde la óptica de lo "mexicano" en la generación del conocimiento social. $\mathrm{Al}$ respecto, Lauro Zavala dice que "la experiencia del espectador de cine es una de las más complejas en la cultura contemporánea...las propuestas teóricas de la estética de la recepción cinemato- 
gráfica permite estudiar las características de cada experiencia particular de ver una película. La guía de análisis... es sólo un mapa de aquello que está en juego en el proceso de ver cine, y es aplicable a cualquier clase de películas" (Zavala, 1993:55).

Por el otro lado, la tradición de la recepción nos lleva a considerar el tipo y el papel del espectador, sus formas de apropiación de los mensajes, y cómo éstos .son circulados en una realidad como la nuestra. "Esta actividad de la audiencia (del espectador), reconocida como recepción, se ha ido mostrando como un proceso, más que de recepción, de acción e interacción, de ambigüedad, de resistencia, de negociación y aun de contradicción... Proceso creativo y a veces impredecible, pero a la vez situado siempre históricamente y enmarcado dentro de coordenadas que permiten observarlo, distinguirlo e invitan a comprenderlo" (Orozco, 1994:70). Al respecto, podemos mencionar como pioneros, los trabajos realizados por Emilio García Riera y por Néstor García Canclini, quienes ya vislumbraron tal necesidad de análisis.

Trabajos que tratan de dar cuenta de los puntos de vista ante una época, como testimonios de una mentalidad, de cómo la presentación en una sala les confiere una nueva importancia, tanto a las películas como a los espectadores: se convierten en objetos de cambio, provocan reuniones, sirven de pretexto para debates, en fin, cómo ejercen una determinada influencia en los públicos.

Investigaciones que se encaminan a saber los tipos de "guiones" propuestos por el celuloide, y de los "guiones" propuestos por las decodificaciones diversas de las cintas por parte del espectador. Porque no podemos negar, ni negarnos a reconocer, que los públicos vieron y ven en el cine las posibilidades de experimentar, de adoptar nuevos hábitos y de ver reiterados (y dramatizados con las voces que les gustaría tener y oír) códigos de costumbre. Podríamos decir que no vamos al cine solamente I soñar, sino que principalmente a aprender, y aprehender, estilos de vida, concepciones del deber ser y del ser social, de la aceptación o negación de valores y prácticas psicosociales que muchas veces ya no nos son ajenas, sino que al verlas ahí representadas nos ayuda a justificarlas, a darles un motivo válido para asumirlas como propias.

Es a través de estos estilos (de los artistas y de los géneros de moda), como el público se ha ido reconociendo y transformando. Es con ello con lo que ese mismo público traspasó la historia personal, cambió el rumbo de la historia nacional de cada país, se apaciguó, se resignó y se encumbró secretamente. La historia de las producciones cinematográficas en nuestro país son muestra palpable de ello: así, el cine de los años iniciales se enfocó a mostrar una nación en ciernes, con sus diversas modalidades de formación; luego, el cine 
de la época de oro, llevó a formar estereotipos del modo de ser "mexicano" o "nacional ", incluso como cliché para el extranjero, y del cual aún nos queda por ahí algún tipo de imagen tal en muchos países del mundo; por su parte, el cine de los sesentas y de los setentas, nos mostró una manera de vivir agitada y más allegada a la realidad, por fin se mostraban las contradicciones sociales, pero al mismo tiempo se mostraba la crisis interna de una industria que dejaba de ser cultural para quererse instaurar como eminentemente comercial; por último, el cine más reciente de los ochentas y lo que va de los noventas, ha mostrado una revigorización que da cuenta de los nuevos modos de construirse socialmente un México de cambios, un México de y con nuevos espectadores, y de nuevas sensibilidades; unas, cintas orientadas hacia la imitación del "american way of life "; otras, enfocadas a discernir eso que queremos llamar la realidad nacional, y las más (y tal vez ambas en conjunto) a tratar de ubicar nuevos sentidos de comprender la vida, de instaurar nuevas cotidianidades desde lo urbano o desde lo rural, o de las raras mezclas de ellas que con la modernidad y la posmodernidad se han encargado de ir construyendo.

$\mathrm{Al}$ respecto, el mismo Lauro Zavala comenta que en las dos décadas pasadas es "el cine surgido a partir de los años 70 y 80 , en el que se superponen elementos del cine clásico y del cine moderno, lo cual da lugar a la presencia simultánea de collage genérico, auto-referencialidad, hiper-realismo y otras estrategias igualmente paradójicas, que a la vez utilizan y ponen en evidencia las convenciones de la representación clásica" (Zavala, 1993:53). Es decir, que así nos vemos, así nos ubicamos, y así nos pensamos. Que así como hay un retorno a la cultura de los años sesentas, así también hay un retorno al cine de estereotipos e imágenes que configuran la mexicanidad de la(s) población(es); y para muestra basta un botón: las películas "enlatadas" porque en aquel entonces se consideraron atentativas contra el orden establecido, ahora son rescatadas y puestas en circulación, tal es el caso de "México, México, ra-ra-ra ", "En la cuerda del hambre" o "La combi asesina ", todas del realizador Gustavo Alatriste. Aparte de que el propio movimiento democratizador y de participación civil que se verifica en estos últimos tiempos ha exigido su exhibición y circulación nacional, también es claro que responde a esa necesidad de ver cómo era esa época, cómo se ha transformado nuestra forma de vida, cómo en fin, se ha construido lo que ahora somos, lo que ahora nos identifica.

Vemos así que el cine se instaura como un mediador eficaz en la constitución de esa nueva experiencia cultural, que es la popular- urbana, pues la gente va al cine a verse, más que en una secuencia de imágenes, en argumen- 
tos que le crean rostros, gestos, modos de hablar y caminar, paisajes, colores, en fin, formas discursivas de lo que somos, de cómo queremos ser, de esos imaginarios que nos creamos en torno y alrededor nuestro. $\mathrm{Y}$ al permitir el cine vemos, nos nacionaliza, nos universaliza, nos cosmopoliza. No nos da nacionalidad, pero si los modos de resentirla, y a nosotros, los analistas de la comunicación y de lo social, nos toca averiguar cómo se resienten esas múltiples nacionalidades por el espectador.

"El hombre, reducido momentáneamente a la condición de espectador, contempla un fenómeno peculiar cuyos rasgos característicos apuntan hacia lo insólito, lo extraordinario, lo excepcional, lo fuera- de lo común" (Gutiérrez, 1983:45). Así nos conducimos como espectadores normales, estándard, como cinéfilos con ciertos grados de conocimientos y reconocimientos del lenguaje cinematográfico; y que además preferimos serlo de esta manera, para apelar más al gusto y al disgusto cuando de ver una película se trata, cuando queremos no reflexionar, sino sólo distraemos, o evadimos de la realidad, como se definía más atrás cuando se hacía mención del mundo imaginario, donde las evasiones de los hechos se dan a partir de la mirada específica de la literatura, de la poesía y de las artes, y qué es el cine, sino un poco de poesía en imágenes.

Esto quiere decir que hay una serie de instituciones sociales, como la familia, la escuela, la religión, el trabajo, los medios, que se interponen, que median las formas de recibir una cinta, formas distintas de significar los mensajes ahí propuestos, negociaciones que formarán espectadores del cine y espectadores con el cine. $Y$ es aquí donde se concretiza la segunda propuesta teórica para acercarse al fenómeno cine desde la comunicación; y es que en la medida en que podamos dar cuenta de las múltiples interrelaciones que asume el espectador con las instituciones a las que pertenece, en esa misma medida estaremos en posibilidad de encontrar las significaciones que produce el mensaje cinematográfico, los sistemas simbólicos de los diversos grupos y gustos, en fin, de la resemantización en la lectura de los mensajes y su expresión en procesos intertextuales que circulan en la cotidianidad, producto de los mismo espectadores.

Y si esto no es así, habría que cuestionar entonces qué mecanismos se asumen como válidos para ver cada domingo por la tarde las películas de Pedro Infante a través del canal de las estrellas, por qué existe un canal de televisión (CMC) dedicado exclusivamente a transmitir cine mexicano durante 18 horas al día, para qué se programan festivales o muestras periódicamente, cómo es posible que se extienda el gusto por la renta de películas, por qué la industria de la piratería del vídeo ha crecido y se ha expandido tan enormemente, en 
fin, por qué seguimos siendo asiduos consumidores de películas. Son puntos de referencia a reflexionar.

\section{Conclusión}

Hemos dado una aproximación sencilla a una problemática que rebasa los límites propios de un ensayo general como éste, pero que aun con todo, son elementos a tomar en cuenta para que desde la comunicación se comiencen a abordar, se comiencen a pensar, y a buscar, modos de operacionalizar instrumentos y herramientas metodológicas con las cuales podamos acercamos cada vez más a él de un modo concreto, con un lenguaje interdisciplinario y con una perspectiva común entre cineastas y comunicólogos, en un trabajo conjunto que por necesidad tendrá que resultar fructífero y alentador para dilucidar soluciones y explicaciones.

Si la investigación cinematográfica desde la comunicación, desde lo comunicativo, quiere conocer cómo se forman y qué proponen esos espectadores con el cine, es necesario dar seguimiento y cuenta de tres puntos fundamentales para explicar la realidad actual de la cuestión cine, no queriendo decir con ello que sean los únicos ni los universales, sino sólo son aquéllos que aparecen como los más urgentes de resolver, siendo éstos, a mi manera particular de ver, los siguientes:

A.- Revisión histórica de las condiciones socio económicas, políticas y culturales por las que ha venido pasando la industria cultural del cine en nuestro país; revisión que nos ayudará a comprender cómo se han construido y constituido los parámetros que la han orientado y que le han marcado su derrotero a lo largo de estos cien años. Con ello estaremos en posibilidad de aventurar pautas de conducta hacia el futuro, hacia una nueva época que se nos viene encima, y de la que apenas contamos con marcos de referencia muy generales y ambiguos como para mínimamente proponer una respuesta viable que nos prepare para enfrentarla, para confrontarla, para decir hacia dónde ir en la producción cinematográfica del próximo centenario, y hacia dónde se orientarán los hábitos de consumo y la construcción de verosímiles de la realidad por parte de los espectadores; cosas que quedan muy complejas como para darles una única respuesta posible y viable, y porque además conllevan una multiplicidad de alternativas y explicaciones, interdisciplinariedades de enfoques, interrelaciones de conceptos, opciones metodológicas que aun están por construirse y contrastarse con la realidad. Aquí, las épocas, los autores, los géneros, los estilos, en fin, todo aquello que envuelve 
la producción cinematográfica tendrá que cuestionarse y resolverse, explicarse y comprenderse, para contar con un futuro un poco más claro;

B.- Ahondar en las teorías y los métodos semióticos y semiológicos, cuyos marcos conceptuales nos permitirán profundizar en la comprensión de los diversos modos de construir los discursos cinematográficos, tanto de los propuestos por el propio medio, como por aquellos propuestos por el mismo espectador en su lectura de las películas, tal y como lo establece Lorenzo Vilches al decir que "el concepto de filmes ... puede situarse en el seno de una teoría de la comunicación donde son el emisor -realizador- y el espectador -destinatario- quienes inauguran tal concepto, a partir del establecimiento de un número determinado de secuencias" (Vilches, $1991: 72$ ); y ello porque no podemos negar que la propia evolución de los sistemas sociales impone un ritmo de hacer cine, una manera particular de presentar una cosmovisión del mundo según el autor o la empresa productora, ni tampoco que esa misma necesidad de alguna manera esté determinada por el propio espectador, por sus necesidades de tener referentes simbólicos de su realidad, porque la "noción de usuario social... nos da la posibilidad de estudiar el texto visual en movimiento como una acción pragmática. En este marco pragmático habría que situar al espectador, como el que actualiza el texto fílmico a través de sus hipótesis de género" (Vilches, 1992:73). Elementos que pueden ser abordados para fines de análisis conforme a una mínima guía cinematográfica (Zavala, 1993) que incluye: condiciones de lectura, título, inicio, imagen, sonido/montaje, códigos estructurales, códigos genéricos, intertextualidad, ideología, final y conclusión, con los cUales el aficionado y el estudioso tienen un parámetro que les permita disfrutar y/o comprender mejor un film, elementos que requerirían todo un texto para ser explicados y ejemplificados a profundidad, por lo que aquí sólo se mencionan remitiendo al lector a la bibliografía citada para su consulta; y por último,

C.- Establecer las relaciones pertinentes y complementarias que nos permitan mapear, elaborar mapas de consumo cultural de las múltiples, y a veces contradictorias, negociaciones con las que el espectador confronta los discursos retornados del cine, los cuales circulan en ámbitos de significación diversos y según las instituciones sociales con las que interactúa, y que tienen como consecuencia una resemantización de los mensajes, una forma distinta de leer los verosímiles de la realidad que el celuloide nos quiere transmitir. Es decir, encontrar esos momentos en que el receptor podrá y tendrá que interpretar siempre, establecer o retomar sistemas simbólicos que den cuenta de su realidad, y es que "los sistemas simbólicos con los que juzgamos el pasado tienen que cambiar, y las cosas y los hechos de antes tienden a cambiar, y 
las cosas y los hechos de antes dejan de ser los mismos" (Paoli, 1994: 1 08). Por ello, el estudio de los sistemas simbólicos también pretende ser una guía para orientarse en esos ramales múltiples de los significados que laten en la pluralidad de cada significante, de cada interpretación del espectador, y del conjunto que unifica un imaginario social, colectivo, verosímil para todos.

Todo ello implica, necesariamente, una labor de conjunto entre aquéllos que entienden de cine, me refiero a productores, directores, técnicos y actores, involucrados en hacer posible el séptimo arte, con aquéllos que tratamos de averiguar qué pasa con la cambiante manera de generar espectadores, es decir, los que desde el ámbito de las Ciencias Sociales queremos abordar la significación social de los medios de comunicación, y explorar esas diversas intertextualidades que propone Lauro Zavala, esas interpretaciones necesarias para dar cuenta de la sociedad moderna y contrastante que tratamos de explicar, ya que, en última instancia, ésa es la finalidad de los estudiosos de lo social, y en particular de los que desde la comunicación tratamos de pensar y repensar cómo se interrelacionan los medios y sus públicos en el actuar cotidiano, cuáles son las estrategias de recepción que construye la audiencia, cómo los medios y sus mensajes proponen modos de entender la vida de los usuarios de acuerdo con las instituciones mediadoras que lo determinan y según también las redes de interactuación que ellos mismos determinan entre sí.

Son éstos, pues, apuntes que merecen ser revisados, cuestionados y reelaborados, adecuados a una realidad multifacética y cambiante, apuntes que quieren generar, si bien nuevas dudas, también proponer alternativas de búsqueda para poder explicar una actividad que tiene muchas formas de ponerle y quitarle "los cascabeles al gato ", motivar a la reflexión del cine como arte, como medio de comunicación, como entretenimiento, como factor ideológico del poder, como posibilidad educativa, en fin, como uno más de las muchas maneras de representar el mundo en el que vivimos. Y obviamente me refiero con esto no sólo al ámbito nacional, o exclusivamente mexicano, sino también al hecho de estructurar una línea de investigación multinacional e interinstitucional que se alimente de las experiencias de otros países, principalmente con los latinoamericanos, porque es con ellos con los que conformamos una amplia experiencia cultural común que nos identifica en muchos y diversos aspectos histórico-sociales.

Si aceptamos que la sociedad mexicana de los últimos 50 años se ha conformado a través de los medios, si aceptamos que las nuevas generaciones son cada vez más visuales y menos textuales, entonces debemos aceptar que los análisis de cine, como los de los otros medios y procesos culturales, son un indicador eficaz para comprender la estructuración de los sistemas simbólicos 
en los imaginarios colectivos, debemos aceptar que ahí hay también una vertiente digna de ser observada.

Esto es lo que se pone a consideración para ser rebatido y criticado, porque sólo así será benéfico para que la industria de los sueños y ensueños, que nos aglutina en estos espacios de reflexión, tome en cuenta las necesidades de sus espectadores, sólo así nos servirá, para aquéllos que estamos involucrados en la formación de profesionistas, para lograr formar comunicólogos con mayores herramientas que les ayuden, (que nos ayuden), a enfrentar los retos de la investigación social, de la investigación particular sobre y acerca de cine desde la comunicación, desde lo comunicativo, en la perspectiva cinematográfica que aquí discernimos.

Quiero cerrar este ensayo con una cita de Massimo Canevacci, donde analiza la mirada actual del cine moderno, mirada que no debemos perder de vista y la cual dice así: "Autores como lean Rouch ou Paolo Pasolini caracterizam-se por un ipo de reinvenção fílmica que utiliza todas as técnicas da fiction verdadeira e propia (dramatização, atores profissionais, estúdios, maquiagem, etc.) para a releitura visual de um tema de caráter -muitas veces- excelentemente antropológico, que, para ser documentado, só pode ser reinventado (Autores como lean Rouch o Paolo Passolini, se caracterizan por un tipo de reinvención fílmica que utiliza todas las técnicas de la ficción verdadera y propia (dramatización, actores profesionales, estudios, maquillaje, etc.) para la relectura visual de un tema de carácter -muchas veces- excelentemente antropológico, y que, para ser documentado, sólo puede ser reinventado)" (Canevacci, 1990: 18). He aquí la lectura de los directores sobre algún tema, he aquí la necesidad de averiguar como se lee por parte del que mira el producto ese mensaje, he aquí la necesidad de reconocer las múltiples lecturas de los textos visuales por parte de los espectadores, por parte de todos aquéllos que gustamos de ir al cine y disfrutar, sea sufriéndolas o gozándolas, las historias que ahí vemos, en las que nos vemos.

\section{Bibliografía}

Alva de la Selva, Alma Rosa, 1996: Itinerarios del consumo cultural En Revista Mexicana de Comunicación, \# 43, febrero/abril de 1996, México.

Aumont, Jacques y Marie M, 1990: Análisis del film, Madrid Paidós. Colección Paidós Comunicación \#42.

Bettetini, Gianfranco, 1994: Tiempo de la expresión cinematográfica, México: Fondo de Cultura Económica, Colección Breviarios del Fondo \# 357. 
Burton, Julianne, 1991: Cine y cambio social en América latina, México: Diana. Colombo, Eduardo, 1993: El imaginario social, Montevideo: Altamira.

De la Torre, Gerardo "100 años de cine en México" En Revista Casa del Tiempo, No 56, octubre de 1996, México: UAM-X.

Dorfles, Gillo, 1993: El devenir de las artes, México: Fondo de Cultura Económica Colección Breviarios \# 170.

García, Gustavo, 1996: “Al final de la pantalla grande” En Revista Mexicana de Comunicación \# 43, febrero/abril de 1996, México

Gomezjara, Francisco A. y Delia Selene de Dios, 1981: Sociología del cine, México: Ed. Diana/SEP. Colección SEP Setentas \# 110.

González Morantes, Carlos, 1996 "Los primeros 100 años del cinematógrafo" En Revista Casa del Tiempo No. 56, octubre de 1996, México: UAM-X.

Gutiérrez Alea, Tomás, 1983: Dialéctica del espectador, México: Federación Editorial Mexicana Serie Arte, Ciencia y Sociedad \#2.

Jarvie, I.C., 1979: El cine como crítica social, México Prisma

Orozco Gómez, Guillermo, 1994: Recepción televisiva y mediaciones La construcción de estrategias por la audiencia, México: Universidad Iberoamericana, Cuadernos del PROIICOM \# 6

Paoli Bolio, José Antonio, 1994: Recepción, significado y sistema simbólico, México: Universidad Iberoamericana Cuadernos del PROIICOM \# 6.

Poloniato, Alicia, 1992 Cine y comunicación, México: Trillas

Sadoul, G., 1986: Las maravillas del cine, México: Fondo de Cultura Económica, Colección Breviarios \# 29.

Sorlin, Pierre, 1981: Sociología del cine. La apertura para la historia del mañana, México: Fondo de Cultura Económica

Zavala, Lauro, 1994: "La mirada múltiple: acerca del espectador del cine" En Bye Bye Lumiére... Investigación sobre cine en México, Guadalajara: Universidad de Guadalajara.

Zavala, Lauro, 1993: "El lenguaje analítico del cine. Convenciones y rupturas en el cine contemporáneo" En Revista Cultural de Excélsior, No 260, mayo de 1993, México.

Zavala, Lauro. "Elementos para el análisis de íntertexlualidad" En La Colmena, No. 9, invierno de 1996, Toluca: Universidad Autónoma del Estado de México.

Zavala, Lauro, 1993: "El suspenso narrativo Del cuento policiaco al cine contemporáneo" En La Jornada Semanal, suplemento del diario La Jornada No. 235, 12 de diciembre de 1993, México.

Vilches, Lorenzo, 1991 La lectura de la imagen, Madrid: Paidós, Colección Paidós Comunicación \#11. 